\title{
Environmental and social-demographic predictors of the southern house mosquito Culex quinquefasciatus in New Orleans, Louisiana
}

\author{
Imelda K. Moise ${ }^{1,2^{*}}$, Claudia Riege ${ }^{3}$ and Ephantus J. Muturi ${ }^{4}$
}

\begin{abstract}
Background: Understanding the major predictors of disease vectors such as mosquitoes can guide the development of effective and timely strategies for mitigating vector-borne disease outbreaks. This study examined the influence of selected environmental, weather and sociodemographic factors on the spatial and temporal distribution of the southern house mosquito Culex quinquefasciatus Say in New Orleans, Louisiana, USA.

Methods: Adult mosquitoes were collected over a 4-year period (2006, 2008, 2009 and 2010) using CDC gravid traps. Socio-demographic predictors were obtained from the United States Census Bureau, 2005-2009 American Community Survey and the City of New Orleans Department of Code Enforcement. Linear mixed effects models and ERDAS image processing software were used for statistical analysis and image processing.

Results: Only two of the 22 predictors examined were significant predictors of $C x$. quinquefasciatus abundance. Mean temperature during the week of mosquito collection was positively associated with $C x$. quinquefasciatus abundance while developed high intensity areas were negatively associated with $C x$. quinquefasciatus abundance.

Conclusion: The findings of this study illustrate the power and utility of integrating biophysical and sociodemographic data using GIS analysis to identify the biophysical and sociodemographic processes that increase the risk of vector mosquito abundance. This knowledge can inform development of accurate predictive models that ensure timely implementation of mosquito control interventions.
\end{abstract}

Keywords: GIS, Remote sensing, New Orleans, Mosquitoes, Hurricane Katrina

\section{Background}

Mosquitoes pose serious economic and public health challenges due to their role in transmission of debilitating and life-threatening diseases of human, veterinary and wildlife significance [1]. These include parasitic diseases such as malaria and lymphatic filariasis and arthropod-borne viruses (arboviruses) such as dengue, chikungunya, Zika and West Nile virus (WNV). Transmission of these diseases follow a clearly defined spatial

\footnotetext{
* Correspondence: moise@miami.edu

'Department of Geography and Regional Studies, College of Arts and

Sciences, University of Miami, 1300 Campo Sano Ave, Coral Gables, FL 33124, USA

${ }^{2}$ Department of Public Health Sciences, Miller School of Medicine, University of Miami, 1120 NW 14th Street, Miami, FL 33136, USA

Full list of author information is available at the end of the article
}

and temporal pattern that is closely associated with mosquito distribution, abundance and vectorial capacity [2, 3]. Each mosquito species has specific biological and ecological requirements that dictate their occurrence, distribution, abundance and vectorial capacity. These requirements encompass a complex network of factors related to climate regimes (e.g. temperature and rainfall), land use, land cover, topography and socioeconomic factors [4-8]. The number and type of factors that influence mosquito distribution can vary markedly between geographical locations even for the same mosquito species [9]. Therefore, identifying the local climatic, environmental, and socioeconomic factors that influence mosquito distribution and abundance can facilitate prediction of disease transmission cycles and timely

(c) The Author(s). 2018 Open Access This article is distributed under the terms of the Creative Commons Attribution 4.0 International License (http://creativecommons.org/licenses/by/4.0/), which permits unrestricted use, distribution, and 
implementation of targeted surveillance and intervention measures.

Natural disasters such as flooding can have major impacts on mosquito-borne disease transmission by modifying the climatic, environmental and socioeconomic drivers of mosquito distribution and abundance. Hurricane Katrina hit the city of New Orleans on August 25, 2005 and presented one of the recent examples of how natural disasters can influence mosquito population dynamics and mosquito-borne disease transmission risk. Levee failures associated with Hurricane Katrina led to massive flooding where approximately $80 \%$ of the city of New Orleans was flooded. These floods created numerous water bodies including abandoned swimming pools that were associated with large populations of mosquito larvae including Culex quinquefasciatus Say [10, 11], the primary vector of $\mathrm{WNV}$ in Louisiana and neighboring states [12]. The observed increase in mosquito larval populations coincided with warm and wet weather, which favored mosquito production [13]. Further studies revealed a 2-fold increase in the number of reported cases of West Nile neuroinvasive disease (WNND) in the hurricane-affected regions of Louisiana and Mississippi compared to previous years [14]. However, there has been no comprehensive studies to identify the major predictors of mosquito abundance in New Orleans post Katrina.

Mosquito-borne disease risk in the aftermath of disasters is likely to vary across space, such that high and low levels of risk are concentrated in specific geographical areas. In addition, the extent to which climatic, neighborhood and environmental characteristics are associated with post-disaster mosquito activities is likely to vary across geographical regions. Therefore, there is potential to use modern scientific geospatial data analysis to integrate both spatial and non-spatial data seamlessly [15] to better understand the spatial and temporal distribution of mosquito vectors in flood prone areas. Moreover, extensive research has shown that when coupled with traditional vector surveillance and environmental monitoring [16, 17], geospatial techniques can help in examining changes in mosquito densities and allow for the identification of climatic, neighborhood and environmental predictors that may be associated with high vector densities [10, 18-24].

The current study uses different geospatial tools to perform a comprehensive analysis aimed at identifying the primary climatic, environmental and sociodemographic predictors of the southern house mosquito $C x$. quinquefasciatus in New Orleans, Louisiana, USA. The findings of this study are crucial for the identification of target hotspots where limited human and fiscal resources can be directed for effective and timely control of vector mosquitoes and prevention and management of disease outbreaks $[4,5]$.

\section{Methods}

\section{Study area}

New Orleans is located in southeastern Louisiana, straddling the Mississippi River, between longitude $90^{\circ} 4{ }^{\prime} 14^{\prime \prime} \mathrm{W}$ and latitude $29^{\circ} 57^{\prime} 53^{\prime \prime} \mathrm{N}$. The lowest point in Louisiana is 8 feet "below" sea level and is located in New Orleans Parish (Orleans Parish and the City of New Orleans are coterminous). The average annual rainfall for the City of New Orleans from 1981 to 2010 is 62.3 inches (2.88 inches more than the average in Louisiana) and the maximum and minimum average monthly temperatures are $90.6^{\circ} \mathrm{F}$ and $41.8^{\circ} \mathrm{F}$, respectively. Peak rainfall generally occurs from June through September. Before Hurricane Katrina, Orleans Parish had 437,186 inhabitants and dealt with mosquitotransmitted viral diseases since its inception as a French colonial city in 1718 . Fortunately, there have been relatively few human cases of WNV, with only 10 reported cases of WNV in 2002 and 11 cases reported in 2011 [25]. The reported cases occurred during the months of July, August and September, the expected high-transmission months.

\section{Mosquito data}

We obtained adult mosquitoes data from the City of New Orleans Mosquito, Termite and Rodent Control Board (NOMTCB). NOMTCB established permanent traps sparsely across New Orleans in the aftermath of Hurricane Katrina in the proximity of habitats producing biting nuisance and disease mosquito. In New Orleans, those areas included low- and medium-developed areas, inner marshes, saltwater or brackish tidal wetlands and the adjacent forested areas containing freshwater wetlands. Notably, NOMTCB has expanded its mosquito surveillance operations since 2010 . Hence, the trap locations used in the current study represented areas that experienced Hurricane Katrina's disastrous flooding on August 29, 2005 and remained representative of the different patterns of land use and land cover changes that have occurred since Hurricane Katrina.

Nineteen CDC gravid traps (John W. Hock Company, Gainesville, FL, USA) and Frommer updraft gravid trap (John W. Hock Company, Gainesville, FL, USA) baited with fish-oil emulsion were used to collect adult mosquito data. The traps operated from March through September during years 2006, 2008, 2009 and 2010. Mosquito capture data were retrieved 3-4 times per week, brought to the NOMTCB laboratory and identified by trained entomologists under a microscope using morphological taxonomic keys of Darsie \& Ward [26]. Nineteen permanent traps were used in the analysis with the annual summaries obtained for years 2008, 2009 and 2010.

\section{Mosquito data processing}

Trapping effort was relatively regular from the three years under study. To avoid issues of spatial autocorrelation in 
abundance, all mosquito capture data at each trap site were calculated as weighted average of a one-kilometer buffer around each trap (based on average effective flight range of the $C x$. quinquefasciatus), monthly and annually.

\section{Environmental data collection and processing}

To quantify land use and land cover (LULC), we derived Landsat 7 EMT (Enhanced Thematic Mapper) satellite imagery patch/row 22/39 (essentially cloud-free) covering New Orleans (dated September 5, 2010) with a ground resolution of $30 \times 30 \mathrm{~m}$. The data were processed using ERDAS (2002) image processing software. Supervised classification was performed to cluster pixels in the subset image data into land cover classes. This was done by defining regions of interest (ROI) that represented each of the four desired LULC classes in the output image corresponding to possible adult $C x$. quinquefasciatus habitats in New Orleans. The ROI's included: developed, open space (mostly vegetation in the form of lawn grasses); developed low intensity (mostly areas with a mixture of constructed materials and vegetation); developed medium intensity (mostly singlefamily housing units); developed high intensity (highly developed areas where people reside or work in high numbers); open water (areas of open water); and woody wetlands (see National Land Cover Database 2006, NLCD2006; http://www.mrlc.gov/nlcd06_leg.php for class definitions). Utmost attention was made in selecting ROI that are homogeneous and correcting for overlaps between classes. We then performed maximum likelihood classification to assign each pixel in the subset image data to the class that had the highest probability.

To derive land cover composition values around each trap location, a one-kilometer buffer was created around each trap (based on average effective flight range of the vector) for each of the three years with observed peak capture (2008, 2009 and 2010) covering the 19 traps under study. We used this buffer to characterize the environment that mosquitoes inhabited around the trap location, considering that in an urban environment, movement is localized due to abundant proximate resources (e.g. blood hosts and container habitats).

\section{Weather data}

Historical monthly temperature and precipitation were obtained from the Louis Armstrong New Orleans International Airport (KMSY) located 10 nautical miles (19 $\mathrm{km}$ ) west of New Orleans' central business district. Although New Orleans has two weather stations, only KMSY weather station data is used since it possessed comprehensive meteorological data. The data included daily maximum temperature, daily minimum temperature and daily total precipitation, which the other weather station did not have.

\section{Sociodemographic data}

We obtained neighborhood and socio-demographic data from the City of New Orleans Department of Code Enforcement (http://www.nola.gov/). Predictors included a list of address-level data on blighted properties [completed property demolition listings (2006-2009), proposed imminent health threat listed properties (2009) and danger of collapse or public nuisance listed properties (2009)]. From the NOMTCB we also obtained data on abandoned swimming pools [22]. Socioeconomic data were obtained from the U.S. Census Bureau, 2005-2009 American Community Survey (ACS). These predictors included population density, change in number of households and median household income.

We then performed an area-weighted average to measure climate, land use, land cover and socio-demographic predictors for the area covered by each of the trap buffers during the three years (2008, 2009 and 2010 three years with comparable trap data). Gravid trap characterization was computed using Imagine Analysis in ArcGIS, version 10.3 [25].

\section{Statistical analyses}

Statistical analyses were conducted using $\mathrm{R}$ version 3.3 .3 software [27]. Only female $C x$. quinquefasciatus were included in the analyses because the abundance of the other mosquito species was too low. Mosquito data were $\log 10$ $(x+1)$ transformed to meet the assumptions of normality. For both temperature and precipitation data, we calculated the average for each week as well as the average for 1 week (Lag 1) and 2 weeks (Lag 2) prior to mosquito collection in order to take into account the cumulative effect of each variable (rainfall and temperature) on mosquito production and abundance [28].

With the additional rainfall and temperature variables (1-week lag and 2-week lag), a total of 22 continuous variables were generated. To test for collinearity and remedy the situation, a linear regression model was fitted to assess the relationship between mosquito abundance and the 22 continuous variables. The package "car" was used to identify and remove highly correlated variables through sequential removal of all variables with a variance inflation factor (VIF) greater than 2.5. Seven variables that met this criterion were used for subsequent analysis. These included variables derived from land cover composition values areas of open water, developed low intensity, developed high intensity and developed open space; weather variable mean temperature $\left({ }^{\circ} \mathrm{F}\right)$; neighborhood recovery variable unattended swimming pools, and sociodemographic variable population density.

The package "Boruti" was used to check which of the 7 retained variables were important and the following six variables were confirmed to be important: mean 
temperature $\left({ }^{\circ} \mathrm{F}\right.$ ), mean temperature at lag 2 (two weeks prior to mosquito collection), mean precipitation at lag 1 , developed, open space, developed high intensity and developed grassland (e.g. golf courses). These six continuous independent variables were analyzed as fixed factors while year was used as a random variable in a linear mixed effects model conducted using "lme4" package.

\section{Results}

\section{Mosquito collection}

From 2008 to 2010, 72,082 adult female mosquitoes belonging to three mosquito species were collected from 19 gravid traps across New Orleans (Table 1). These included Aedes aegypti (Linnaeus in Hasselquist), Aedes albopictus (Skuse) and Cx. quinquefasciatus, with the $C x$. quinquefasciatus accounting for $82.4 \%$ of the total collection. The mean annual abundance of $C x$. quinquefasciatus was summarized across all 19 traps (Fig. 1).

\section{Mosquito abundance change over time}

There was significant temporal (ANOVA: $F=5.922, d f=$ $2.51,100, P<0.002$ ) and inter-annual variation in the abundance of Cx. quinquefasciatus (Fig. 2). Significantly more mosquitoes were collected in $2009(n=33,667)$ and $2010(n=26,489)$ compared to $2008(n=9431)(P<$ 0.01). Peak mosquito populations also occurred much earlier in 2009 and 2010 (May) compared to 2008 (July). This suggests that the peak extended over June-July in 2008 and in 2010 (May-June).

\section{Association of LULC, climate and socio-demographic predictors with mosquito abundance}

The random variable year accounted for $4.0 \%$ of the total observed variance suggesting it had little influence on adult mosquito abundance. Mosquito abundance was positively associated with mean temperature of the week when the mosquitoes were collected and negatively associated with highly developed areas, in particular areas where people reside or work in high numbers (Table 2). None of the other variables was significantly associated with mosquito abundance.

\section{Discussion}

The aim of this study was to examine the environmental, climatic and sociodemographic factors that influence the spatial and temporal distribution of $C x$. quinquefasciatus abundance in New Orleans, Louisiana, from 2006 to 2010. Female host-seeking $C x$. quinquefasciatus were captured with $\mathrm{CDC}$ gravid traps, so their abundances reflected the blood mealseeking behavior of this species. Our findings show that mosquito abundance was low in 2008 and increased dramatically in 2009. In New Orleans, this finding may be attributable to the accelerated and targeted surveillance and control efforts that were implemented by NOMTCB after Hurricane Katrina, which may have contributed to the prolonged reduction in adult mosquito abundance [22].

Another important finding was that $C x$. quinquefasciatus abundance was positively associated with mean temperature of the week when mosquitoes were collected and was negatively associated with highly developed areas. The former finding is concordant with previous findings [29], and other studies, which found temperature as influencing oviposition and habitant selection by $C x$. quinquefasciatus [30, 31]. These results also seem to be consistent with other research, which found temperature to accelerate the development of mosquito larvae and higher mosquito abundance [3236]. It can therefore, be assumed that our models depicted the positive impacts of temperature at a biologically probable time lag that could provide for a basis for planning mosquito control activities in New Orleans. This is important because $C x$. quinquefasciatus plays a very important role in the enzootic cycle due to its susceptibility to viral infection from feeding on infected blood meal and feeding preference for mammals instead of birds in urban environments [37-40].

One unanticipated finding was the negative association with highly developed areas and $C x$. quinquefasciatus abundance. This outcome is contrary to that of previous studies that linked highly developed areas with WNV in New York [41] but they are broadly consistent with earlier studies that found low mosquito densities in highly developed areas in urban settings $[29,30]$. In addition, in New Orleans, Cx. quinquefasciatus has been reported to oviposit in different water sources and achieving high larval densities in water with high organic content (e.g. sewage treatment ponds, drains) and mucky waters including abandoned swimming pools [10, 11, 23, 42]. Therefore, this finding was unexpected and suggests that the observed lower Cx. quinquefasciatus abundance is likely the result of NOMTCB control interventions targeted at eliminating larval sources rather than prevailing unaltered levels [22]. This finding, while preliminary, supports the need for continued mosquito control efforts in areas where surveillance indicates presence and increased risk of mosquitoes. The potential impacts of NOMTCB control interventions on vector abundance requires further study.

With the exception of mean temperature and highly developed areas, environmental and sociodemographic factors were not associated with $C x$. quinquefasciatus abundance in New Orleans. These findings could be reflective of our study setting, a city that augmented mosquito control and outreach activities in the aftermath of Hurricane Katrina. 
Table 1 Number of mosquito species collected in each genus by study site in New Orleans summarized by month from spring 2006 to summer 2010

\begin{tabular}{|c|c|c|c|c|c|c|}
\hline 5.Year & Month & No. of collections & $A E G \cap(\%)$ & $A L B \cap(\%)$ & CXQ $n(\%)$ & Total no. of mosquitoes \\
\hline 2006 & March & 30 & $0(0.00)$ & $18(0.04)$ & $46(0.06)$ & 64 \\
\hline 2006 & April & 29 & $1(0.16)$ & $2(0.00)$ & $40(0.06)$ & 43 \\
\hline 2006 & May & 34 & $38(5.89)$ & $12(0.03)$ & $164(0.23)$ & 214 \\
\hline 2006 & June & 27 & $29(4.50)$ & $2(0.00)$ & $316(0.44)$ & 347 \\
\hline 2006 & July & 34 & $31(4.81)$ & ns & $291(0.41)$ & 322 \\
\hline 2006 & August & 54 & $105(16.28)$ & $5(0.01)$ & $343(0.48)$ & 453 \\
\hline 2006 & September & 44 & $36(5.58)$ & $3(0.01)$ & $228(0.32)$ & 267 \\
\hline 2008 & March & 4 & $0(0.00)$ & $0(0.00)$ & $2(0.00)$ & 2 \\
\hline 2008 & April & 56 & $8(1.24)$ & $3(0.01)$ & $634(0.89)$ & 645 \\
\hline 2008 & May & 55 & $9(1.40)$ & $7(0.02)$ & $1592(2.24)$ & 1608 \\
\hline 2008 & June & 56 & $26(4.03)$ & $10(0.02)$ & $2558(3.60)$ & 2594 \\
\hline 2008 & July & 70 & $50(7.73)$ & $30(0.07)$ & $3154(4.44)$ & 3234 \\
\hline 2008 & August & 58 & $43(6.67)$ & $13(0.03)$ & $1493(2.10)$ & 1549 \\
\hline 2009 & March & 54 & $1(0.16)$ & $2(0.00)$ & $881(1.24)$ & 884 \\
\hline 2009 & April & 48 & $6(0.93)$ & $2(0.00)$ & 2847 (3.60) & 2,855 \\
\hline 2009 & May & 67 & $19(2.95)$ & $16(0.04)$ & $12,646(17.81)$ & 12,681 \\
\hline 2009 & June & 75 & $16(2.48)$ & $11(0.03)$ & 5772 (8.13) & 5799 \\
\hline 2009 & July & 53 & $18(2.79)$ & $51(0.12)$ & 2354 (3.31) & 2423 \\
\hline 2009 & August & 58 & $54(8.37)$ & $56(0.13)$ & 3501 (4.93) & 3611 \\
\hline 2009 & September & 63 & $55(8.37)$ & $43(0.41)$ & $5666(7.98)$ & 5764 \\
\hline 2010 & March & 38 & $0(0.00)$ & $0(0.00)$ & $5(0.01)$ & 5 \\
\hline 2010 & April & 38 & $0(0.00)$ & $3(0.01)$ & $380(0.54)$ & 383 \\
\hline 2010 & May & 75 & $9(1.10)$ & $29(0.07)$ & $9384(13.21)$ & 9422 \\
\hline 2010 & June & 71 & $41(6.36)$ & $20(0.05)$ & 8894 (12.52) & 8955 \\
\hline 2010 & July & 52 & $18(2.79)$ & $47(0.11)$ & $4867(6.85)$ & 4932 \\
\hline 2010 & August & 91 & $28(4.34)$ & $30(0.07)$ & $2841(4.00)$ & 2899 \\
\hline 2010 & September & 18 & $4(0.62)$ & $5(0.01)$ & $118(0.17)$ & 127 \\
\hline Total & & & 645 & 420 & 71,017 & 72,082 \\
\hline
\end{tabular}

Abbreviations: CXQ Culex quinquefasciatus, AEG Ae. aegypti, ALB Ae. albopictus, ns not sampled

Furthermore, given the unique climate, land use and hydrology of New Orleans, the details of these environmental and sociodemographic relationships will probably differ from other areas of the United States. Further studies, which consider these variables in other southeastern United States, will need to be undertaken.

Methodologically, our findings also highlight the importance of beefing up traditional non-spatially explicit methods with geospatial analysis (e.g. GIS) and satellite data to integrate environmental parameters in analyzing the spatiotemporal distribution of mosquito population and the underlying predictors. These methods allowed both the integration of biophysical and sociodemographic data, with the potential to better guide mosquito surveillance and control interventions [21, 43-45].

This study had two major weaknesses that limited the scope of analyses. First, we did not have preKatrina data in order to be able to compare changes in mosquito abundance before, during and after the Hurricane Katrina. However, our data still provides important knowledge on the key environmental factors that influence the abundance of one of the primary vectors of WNV in southeastern United States. Second, our attempt to validate any form of model fitting was hindered by the limited number of traps used in the current study, with only 19 traps. Additional studies using a much larger sample size could be more revealing. 


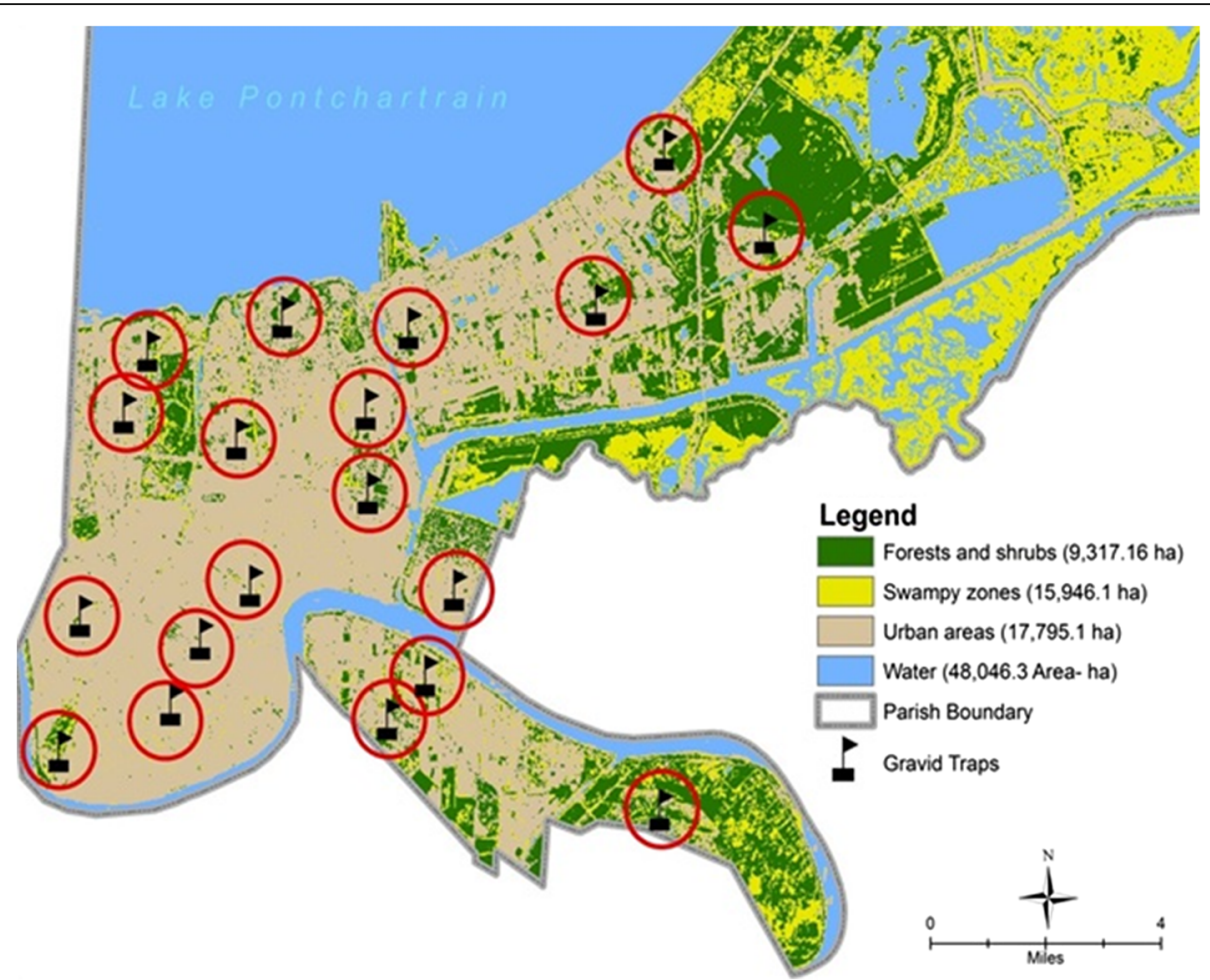

Fig. 1 Nineteen trap locations where adult mosquitoes were collected from March 2009 to September 2010. The 1-km radius surrounding each trap used in analysis is outlined in red. Traps are overlaid on a land cover/land use map

\section{Conclusions}

We examined the spatial and temporal changes in $C x$. quinquefasciatus abundance in New Orleans (2006, 2008, 2009 and 2010) and association with environmental and social demographic predictors. Culex quinquefasciatus abundance increased significantly and had earlier peaks in 2009 and 2010 than in 2008 . High mosquito abundance was negatively associated with highly developed areas while mean temperature during the week of mosquito collection was positively associated with $C x$. quinquefasciatus abundance. Findings illustrate the power and utility of integrating

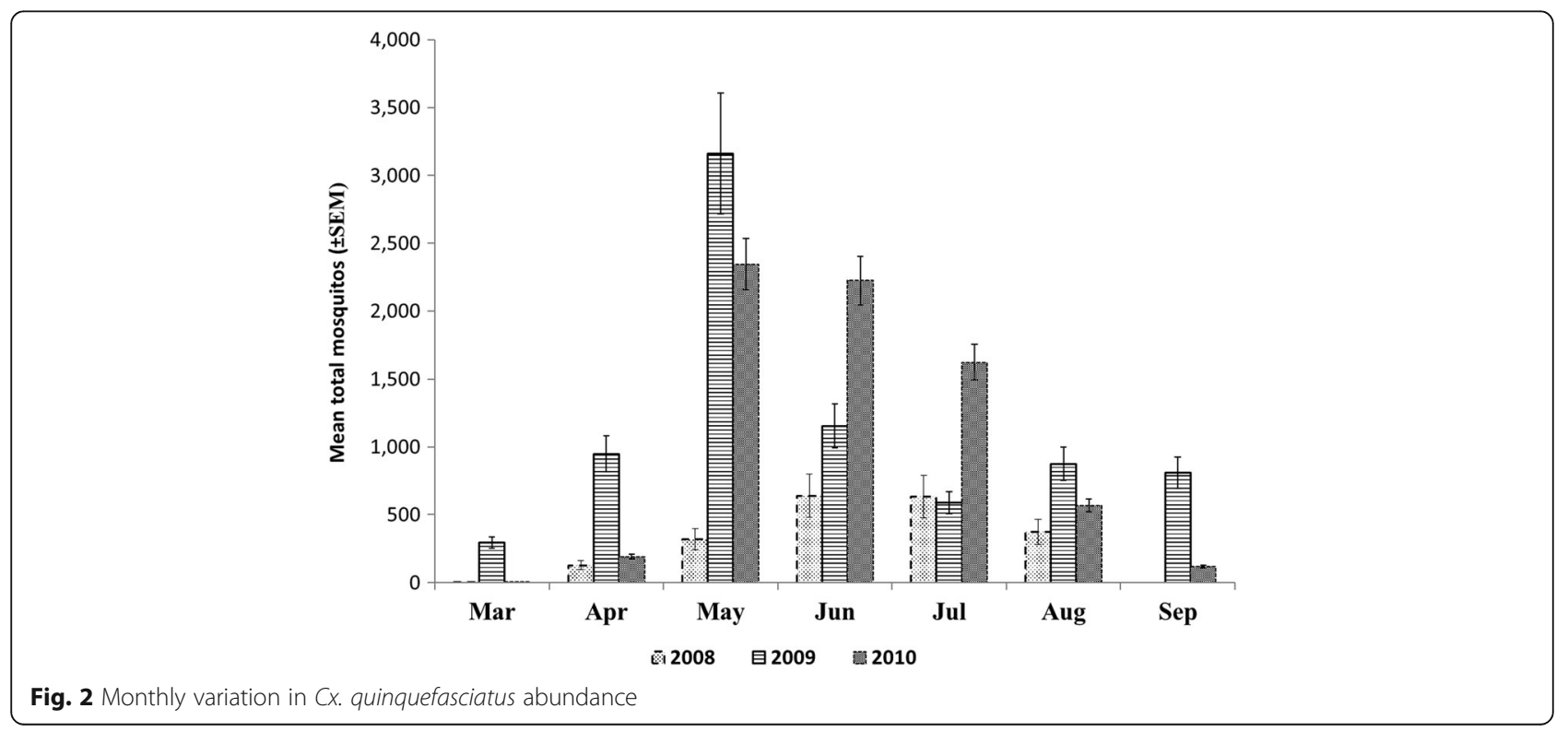


Table 2 LULC, weather and sociodemographic predictors of CX. quinquefasciatus abundance, New Orleans, 2009 and 2010

\begin{tabular}{|c|c|c|c|c|c|}
\hline & Estimate & SE & $t$-value & Chi-square & $P$-value \\
\hline (Intercept) & 1.08 & 0.12 & 9.08 & & \\
\hline Mean temperature $\left({ }^{\circ} \mathrm{F}\right)$ & 0.17 & 0.04 & 4.28 & 18.29 & $<0.001$ \\
\hline Lag 1 mean temperature $\left({ }^{\circ} \mathrm{F}\right)$ & -0.03 & 0.04 & -0.82 & 0.68 & 0.41 \\
\hline Lag 1 mean precipitation & 0.05 & 0.03 & 1.70 & 2.88 & 0.09 \\
\hline Lag 2 mean temperature ( $\left.{ }^{\circ} \mathrm{F}\right)$ & 0.00 & 0.04 & 0.04 & 0.00 & 0.97 \\
\hline Developed, open space areas & 0.00 & 0.03 & 0.09 & 0.01 & 0.93 \\
\hline Developed high intensity areas & -0.18 & 0.03 & -5.66 & 32.06 & $<0.001$ \\
\hline Developed grassland areas & 0.05 & 0.03 & 1.63 & 2.66 & 0.10 \\
\hline
\end{tabular}

Abbreviation: SE standard error

biophysical and sociodemographic data using GIS analysis to assess influences of biophysical and sociodemographic processes that generate heterogeneity in critical $C x$. quinquefasciatus mosquito abundance that inform the development of accurate predictive models that ensure timely implementation of mosquito control interventions.

\section{Acknowledgements}

We are grateful to various City of New Orleans departments, the City of New Orleans Mosquito, Termite and Rodent Control Board, the Greater New Orleans Data Center and the Department of Code Enforcement for their support and for providing data used in the study. We appreciate the constant participation of the City of New Orleans Mosquito, Termite and Rodent Control Board staff in the study. Any opinions, findings, conclusions, or recommendations expressed in this publication are those of the author(s) and do not necessarily reflect the view of the U.S. Department of Agriculture. Mention of trade names or commercial products in this publication is solely for providing specific information and does not imply recommendation or endorsement by the U.S. Department of Agriculture. USDA is an equal opportunity provider and employer.

\section{Availability of data and materials}

Environmental data used in this study are downloadable at the National Land Cover Database (http://www.mrlc.gov/nlcd06_leg.php), socioeconomic data are available at the 2005-2009 U.S. Bureau of the Census American Community Survey (ACS) and mosquito data used in the present study are available from the second corresponding author upon reasonable request.

\section{Authors' contributions}

IM was involved in the conceptualization, research design, geospatial analysis, execution and write-up of the first draft of the manuscript. CR contributed to data collection, database design and reviewed the first draft manuscript; EJM conducted data analysis and contributed to the writing and reviewing of the manuscript. All authors were involved in the preparation of the manuscript. All authors read and approved the final manuscript.

\section{Ethics approval and consent to participate}

The Institutional Review Board at the University of Illinois at Urbana-Champaign approved all protocols used in this study (IRB Protocol Number: 11074).

\section{Competing interests}

The authors declare that they have no competing interests.

\section{Publisher's Note}

Springer Nature remains neutral with regard to jurisdictional claims in published maps and institutional affiliations.

\section{Author details}

'Department of Geography and Regional Studies, College of Arts and Sciences, University of Miami, 1300 Campo Sano Ave, Coral Gables, FL 33124,
USA. ${ }^{2}$ Department of Public Health Sciences, Miller School of Medicine, University of Miami, 1120 NW 14th Street, Miami, FL 33136, USA. ${ }^{3} \mathrm{New}$ Orleans Mosquito, Termite and Rodent Control Board, 2100 Leon C. Simon, New Orleans, LA 70122, USA. ${ }^{4}$ Crop Bioprotection Research Unit, USDA, ARS, 1815 N. University St, Peoria, IL 61604, USA.

Received: 15 January 2018 Accepted: 5 April 2018

Published online: 17 April 2018

References

1. Fernandes JN, Moise IK, Maranto GL, Beier JC. Revamping mosquito-borne disease control to tackle future threats. Trends Parasitol. 2018. https://doi. org/10.1016/j.pt.2018.01.005.

2. Smith DL, Drakeley CJ, Chiyaka C, Hay SI. A quantitative analysis of transmission efficiency versus intensity for malaria. Nat Commun. 2010;1:108.

3. Mbogo C, Mwangangi J, Nzovu J, Gu W, Yan G, Gunter JT, et al. Spatial and temporal heterogeneity of Anopheles mosquitoes and Plasmodium falciparum transmission along the Kenyan coast. Am J Trop Med Hyg. 2003; 68:734-42.

4. Walker KR, Joy TK, Ellers-Kirk C, Ramberg FB. Human and environmental factors affecting Aedes aegypti distribution in an arid urban environment. J Am Mosq Control Assoc. 2011;27(2):135-41.

5. Ruiz OM, Carmen T, Thomas JM, Connie A, Uriel K. Environmental and social determinants of human risk during a West Nile virus outbreak in the greater Chicago area, 2002. Int J Health Geogr. 2004;3:8.

6. Kunkel K, Novak R, Lampman R, Modeling GW. the impact of variable climatic factors on the crossover of Culex restuans and Culex pipiens (Diptera: Culicidae), vectors of West Nile virus in Illinois. Am J Trop Med Hyg. 2006;74:168-73.

7. Afrane YA, Little TJ, Lawson BW, Githeko AK, Yan G. Deforestation and vectorial capacity of Anopheles gambiae Giles mosquitoes in malaria transmission, Kenya. Emerg Infect Dis. 2008;14:1533-8.

8. Alto BW, Juliano SA. Precipitation and temperature effects on populations of Aedes albopictus (Diptera: Culicidae): implications for range expansion. J Med Entomol. 2001;38:646-56.

9. Sallam MF, Fizer C, Pilant AN, Whung P. Systematic review: land cover, meteorological, and socioeconomic determinants of Aedes mosquito habitat for reisk mapping. Inter J Environ Res Publ Hlth. 2017;14:1230.

10. Caillouët KA, Carlson JC, Wesson D, Jordan F. Colonization of abandoned swimming pools by larval mosquitoes and their predators following Hurricane Katrina. J Vector Ecol. 2008;33:166-72.

11. Marten G, Carroll M, Harrison C, Nguyen M, Riegel C, Thompson G, et al. Using Gambusia to control mosquito larvae in abandoned swimming pools. New Orleans Mosquito, Termite, and Rodent Control Board. Original posting: May, 2010. 69 pp.

12. Godsey MS, Nasci R, Savage HM, Aspen S, King R, Powers AM, et al. West Nile virus-infected mosquitoes, Louisiana, 2002. Emerg Infect Dis. 2005;11: 1399-404.

13. Manuel J. In Katrina's wake. Environ Health Perspect. 2006;114:A32-9.

14. Caillouët KA, Michaels SR, Xiong X, Foppa I, Wesson DM. Increase in West Nile neuroinvasive disease after Hurricane Katrina. Emerg Infect Dis. 2008:14:804-7.

15. Moise IK, Ruiz MO. Hospitalizations for substance abuse disorders before and after Hurricane Katrina: spatial clustering and area-level predictors, New Orleans, 2004 and 2008. Prev Chronic Dis. 2016;13:E145. 
16. Cleckner HL, Allen TR, Bellows AS. Remote sensing and modeling of mosquito abundance and habitats in coastal Virginia, USA. Remote Sensing. 2011;3:2663-81.

17. Curtis A, Curtis JW, Shook E, Smith S, Jefferis E, Porter L, et al. Spatial video geonarratives and health: case studies in post-disaster recovery, crime, mosquito control and tuberculosis in the homeless. Int J Health Geogr. 2015;14:22.

18. Ruiz MO, Tedesco C, McTighe TJ, Austin C, Kitron U. Environmental and social determinants of human risk during a West Nile virus outbreak in the greater Chicago area, 2002. Int J Health Geogr. 2004;3:8.

19. Troyo A, Fuller DO, Calderón-Arguedas O, Beier JC. A geographical sampling method for surveys of mosquito larvae in an urban area using highresolution satellite imagery. J Vector Ecol. 2008;33:1-7.

20. Ezenwa VO, Milheim LE, Coffey MF, Godsey MS, King RJ, Guptill SC. Land cover variation and West Nile virus prevalence: patterns, processes, and implications for disease control. Vector Borne Zoonotic Dis. 2007;7:173-80.

21. Ruiz MO, Chaves LF, Hamer GL, Sun T, Brown WM, Walker ED, et al. Local impact of temperature and precipitation on West Nile virus infection in Culex species mosquitoes in northeast Illinois, USA. Parasit Vectors. 2010;3:19.

22. Moise IK, Brown KS, Riegel C, Kalipeni E, Ruiz MO. Geographic assessment of unattended swimming pools in post-Katrina New Orleans, 2006-2008. Ann Assoc Am Geogr. 2013;103:1160-75.

23. Reisen WK, Takahashi RM, Carroll BD, Quiring R. Delinquent mortgages, neglected swimming pools, and West Nile virus, California. Emerg Infect Dis. 2008;14:1747-9.

24. Samson DM, Archer RS, Alimi TO, Arheart KK, Impoinvil DE, Oscar R, et al. New baseline environmental assessment of mosquito ecology in northern Haiti during increased urbanization. J Vector Ecol. 2015;40:46-58.

25. Louisiana Office of Public Health. West Nile Encephalitis or Neuro-Invasive Disease (WNV-NID): Encephalitis WNV Annual Report. Section IDE. New Orleans, LA: Louisiana Office of Public Health, Infectious Disease Epidemiology Section; 2016.

26. Darsie $\mathrm{R}$, Ward R. Identification and geographical distribution of the mosquitoes of North America, North of Mexico. Gainesville, FL, USA: University Press of Florida; 2005

27. R Core Team. R: A Language and Environment for Statistical Computing. 3.2. 5 ed. Vienna, Austria: R Foundation for Statistical Computing; 2016.

28. Jacups SP, Carter J, Kurucz N, McDonnell J, Whelan PI. Determining meteorological drivers of salt marsh mosquito peaks in tropical northern Australia. J Vector Ecol. 2015:40:277-81.

29. Chuang T-W, Hildreth MB, Vanroekel DL, Wimberly MC. Weather and land cover influences on mosquito populations in Sioux Falls, South Dakota. J Med Entomol. 2011;48:669-79.

30. Kang DS, Tomas R, Sim C. The effects of temperature and precipitation on Culex quinquefasciatus (Diptera: Culicidae) abundance: a case study in the Greater Waco City, Texas. Vector Biol J. 2017;2:1. https://doi.org/10.4172/ 2473-4810.1000116.

31. Chaves LF, Kitron UD. Weather variability impacts on oviposition dynamics of the southern house mosquito at intermediate time scales. Bull Entomol Res. 2011;101:633-41.

32. Ciota AT, Matacchiero AC, Kilpatrick AM, Kramer LD. The effect of temperature on life history traits of Culex mosquitoes. J Med Entomol. 2014;51:55-62.

33. Grech MG, Sartor PD, Almirón WR, Ludueña-Almeida FF. Effect of temperature on life history traits during immature development of Aedes aegypti and Culex quinquefasciatus (Diptera: Culicidae) from Córdoba city, Argentina. Acta Trop. 2015;146:1-6.

34. Muturi EJ, Lampman R, Costanzo K, Alto BW. Effect of temperature and insecticide stress on life-history traits of Culex restuans and Aedes albopictus (Diptera: Culicidae). J Med Entomol. 2011;48:243-50.

35. Muturi EJ, Blackshear M, Montgomery A. Temperature and densitydependent effects of larval environment on Aedes aegypti competence for an alphavirus. J Vector Ecol. 2012;37:154-61

36. Gardner AM, Hamer GL, Hines AM, Newman CM, Walker ED, Ruiz MO. Weather variability affects abundance of larval Culex (Diptera: Culicidae) in storm water catch basins in suburban Chicago. J Med Entomol. 2012;49:270-6.

37. Eastwood G, Kramer LD, Goodman SJ, Cunningham AA. West Nile Virus vector competency of Culex quinquefasciatus mosquitoes in the Galápagos Islands. Am J Trop Med Hyg. 2011;85:426-33.
38. Leggewie M, Badusche M, Rudolf M, Jansen S, Börstler J, Krumkamp R, et al. Culex pipiens and Culex torrentium populations from central Europe are susceptible to West Nile virus infection. One Health. 2016;2:88-94.

39. Glaser RL, Meola MA. The native Wolbachia endosymbionts of Drosophila melanogaster and Culex quinquefasciatus increase host resistance to West Nile virus infection. PLoS One. 2010;5:e11977.

40. Goddard LB, Roth AE, Reisen WK, Scott TW. Vector competence of California mosquitoes for West Nile virus. Emerg Infect Dis. 2002;8:1385-91.

41. Rappole JH, Derrickson SR, Hubálek Z. Migratory birds and spread of West Nile virus in the Western Hemisphere. Emerg Infect Dis. 2000;6:319-28.

42. Calhoun LM, Avery M, Jones L, Gunarto K, King R, Roberts J, et al. Combined sewage overflows (CSO) are major urban breeding sites for Culex quinquefasciatus in Atlanta, Georgia. Am J Trop Med Hyg. 2007;77:478-84.

43. Kitron U, Clennon JA, Cecere MC, Gürtler RE, King CH, Vazquez-Prokopec G. Upscale or downscale: applications of fine scale remotely sensed data to Chagas disease in Argentina and schistosomiasis in Kenya. Geospat Health. 2006;1:49-58.

44. Eisen L, Lozano-Fuentes S. Use of mapping and spatial and space-time modeling approaches in operational control of Aedes aegypti and dengue. PLoS Negl Trop Dis. 2009;3:e411.

45. Dohm DJ, O'Guinn ML, Turell MJ. Effect of environmental temperature on the ability of Culex pipiens (Diptera: Culicidae) to transmit West Nile virus. J Med Entomol. 2002;39:221-5.

\section{Ready to submit your research? Choose BMC and benefit from:}

- fast, convenient online submission

- thorough peer review by experienced researchers in your field

- rapid publication on acceptance

- support for research data, including large and complex data types

- gold Open Access which fosters wider collaboration and increased citations

- maximum visibility for your research: over $100 \mathrm{M}$ website views per year

At BMC, research is always in progress.

Learn more biomedcentral.com/submissions 